\title{
Anxiety, Stress-Related Factors, and Blood Pressure in Young Adults
}

\author{
Nicola Mucci ${ }^{*}$, Gabriele Giorgi ${ }^{2}$, Stefano De Pasquale Ceratti ${ }^{2}$, Javier Fiz-Pérez ${ }^{2}$, \\ Federico $\mathrm{Mucci}^{3}$ and Giulio Arcangeli ${ }^{1}$
}

${ }^{1}$ Department of Experimental and Clinical Medicine, University of Florence, Florence, Italy, ${ }^{2}$ Department of Psychology, European University of Rome, Rome, Italy, ${ }^{3}$ Department of Clinical and Experimental Medicine, University of Pisa, Pisa, Italy

Hypertension $(\mathrm{HT})$ is a long-term medical condition characterized by persistently elevated blood pressure (BP) in the arterial vessels. Although HT initially is an asymptomatic condition, it chronically evolves into a major risk factor for cardiovascular, cerebrovascular, and renal diseases that, in turn, represent crucial causes of morbidity and mortality in industrialized countries. HT is a complex disorder that is estimated to affect more than a quarter of the world's adult population. It is classified on the basis of both its pathophysiology (primary and secondary $\mathrm{HT}$ ) and on the resting BP values (elevated systolic, diastolic, and pulse pressure). It originates from a complicated interaction of genes and several environmental risk factors including aging, smoking, lack of exercise, overweight and obesity, elevated salt intake, stress, depression, and anxiety. Anxiety and depressive disorders are the most commonly diagnosed mental disorders, affecting millions of people each year and impairing every aspect of everyday life, both of them characterized by affective, cognitive, psychomotor, and neurovegetative symptoms. Moreover, work-related stress has been considered as an important risk factor for HT and cardiovascular diseases (CVDs). Although different authors have investigated and suggested possible relations between $\mathrm{HT}$, stress, anxiety, and depression during the last decades, a full understanding of the underlying pathophysiological mechanisms has not been satisfactorily achieved, especially in young adults. The aim of this study was to investigate the impact of anxiety and workrelated stress in the development of $\mathrm{HT}$ amongst young health care profession students and the possible related consequences of early CVDs.

Keywords: blood pressure, anxiety, work-related stress, students, health care professions, health promotion, workplace, occupational medicine

\section{INTRODUCTION}

The blood pressure (BP) is the pressure that the blood flow exerts against the walls of blood vessels. It varies in the different parts of the human body according to the phases of contraction of heart and to the conditions of health, exercise, stress, etc. If the term BP is used without further specification, usually refers by antonomasia to the arterial pressure in the systemic circulation. BP is usually expressed in terms of the systolic BP (SBP, maximum pressure), over diastolic BP (DBP, minimum pressure) (Hodgkinson et al., 2015). It is usually measured at a person's upper arm and is measured in millimeters of mercury $(\mathrm{mmHg})$ because the traditional device used to measure $\mathrm{BP}$, a sphygmomanometer, used a glass column filled with mercury and calibrated in millimeters. 
Normal resting BP in an adult is within the range of $100-$ $140 \mathrm{mmHg}$ systolic and $60-90 \mathrm{mmHg}$ diastolic (Mancia et al., 2013).

Moreover, during the last two decades, pulse pressure (PP), defined as the difference between SBP and DBP within a normal range of 30-80 $\mathrm{mmHg}$, has received growing attention as an independent predictor of cardiovascular risk (Tin et al., 2002). Some authors, in a meta-analysis of 2,000 combining studies that previously examinated over 8,000 elderly subjects, demonstrated that the risk of major cardiovascular complications and mortality increased by nearly $20 \%$ within an increase of $10 \mathrm{~mm} \mathrm{Hg}$ in PP (Blacher et al., 2000). On the other hand, studies on young adults are still meager and results often contradictory, therefore motivating the increasing need of researching on these subjects in order to fulfill an adequate prevention of such invalidating diseases (Ritvanen et al., 2003; Riese et al., 2004).

Hypertension (HT) is either defined as a transitory or persistent elevation of arterial BP with, arbitrarily, a systolic measures $>160 \mathrm{mmHg}$ or more and diastolic measures $>90 \mathrm{mmHg}$ (Wright and Diamond, 2006; Poulter et al., 2015). HT represents a worldwide problem afflicting more than a quarter of the world's adult population, in both developed (333 million) and in developing countries (639 million) (Santulli, 2013). It represents a major preventable risk factor for premature death and disability and, in particular, a crucial risk factor in the development of cardiovascular diseases (CVDs), such as hypertensive heart disease, coronary artery disease, stroke, aortic aneurysm, peripheral artery disease, cerebrovascular disease, and chronic kidney disease (Jennings and Touyz, 2013; Floyd, 2015).

Coronary heart diseases (CHDs) in men are negligible until the age of 40 years, they emerge between 40 and 50 years and then grow exponentially with age; in women occur at ages 50 60 years and grow rapidly. The disadvantage of men compared to women is more pronounced in young people and tends to decrease with age: the lowest frequency of ischemic heart disease in women than in men is particularly evident in the reproductive age. The prevalence difference between the sexes is accompanied by differences in clinical manifestations: women suffer, in fact, more frequently from sudden death, silent heart attack, and angina pectoris (Maas and Appelman, 2010; Khamis et al., 2016).

Notwithstanding the strategies of screening, prevention, and treatment, the prevalence of HT is increasing throughout the lifespan, along with the increasing of population aging, sedentary life-style and high-calorie food intake (Hansen et al., 2007; Floyd, 2015). Moreover, an appropriate BP control is achieved only by less than a half of patients receiving treatment (Lewington et al., 2002; Falaschetti et al., 2014). Last but not least, the financial burden for EU health systems associated with CVDs has been estimated to be nearly $€ 110$ billion in 2006 (corresponding to $10 \%$ of total health care expenditure across $\mathrm{EU}$ ), and the direct cost associated with HT was estimated to be $€ 51.3$ billion (Mennini et al., 2015).

Although the etiology of HT has been widely studied in depth during the last decades, it still remains far to be completely understood, as it results from a complicated interaction of genetic and several environmental risk factors. Furthermore, the development of HT is associated with several demographic, lifestyle, and psychosocial variables (Pilic et al., 2016). Examples of demographic variables related to CVDs are aging, ethnic group, geographic regions, lower income, lower educational attainment, difficulty of access, and lower quality of public health services (Ferguson et al., 2008; Hosey et al., 2014). As far as lifestyle variables are concerned, robust evidence is available that aging, smoking, alcohol consumption, lack of exercise, disruption of circadian rhythms, diet poor in fruit and vegetables, overweight, obesity [pathological elevation of the body mass index (BMI)] and elevated salt intake are related to an increased risk of HT and any CVDs (Tanuseputro et al., 2003; Pilic et al., 2016).

Other risk factors, such as psychosocial ones and mental disorders, have also been investigated by several authors, nevertheless the relation with HT results less clear and, sometimes, controversial (Kessler et al., 2005; Sparrenberger et al., 2009; Spruill, 2010; Graham and Smith, 2016; Mermerelis et al., 2016; Ventura and Lavie, 2016). However, literature agrees that perceived stress amongst health care profession students is high and that a significant number of them may develop a psychological morbidity (Pryjmachuk and Richards, 2008; Nechita et al., 2014; Wallace et al., 2015).

Work-related stress is involved in the development of HT and a consistent number of studies examined different common work-related aspects including job insecurity, strain and control (job quality), satisfaction, wages, work hours, and perceived dissatisfaction (Baldasseroni et al., 2005; Rau, 2006; Wright et al., 2011; Johansson et al., 2012; Leigh and Du, 2012; James et al., 2013; Modrek and Cullen, 2013; Smith et al., 2013; Ford, 2014). Other research had already shown how stress may cause changes in BP, increased cholesterol blood levels, triglycerides, hematocrit, fibrinogen, and blood fluidity. Mental stress may cause an abnormal activation of the sympathetic nervous system (SNS) triggering hormonal cascades that interfere with BP, increased coagulation and platelet activity, factors that can act as "triggers" of cerebrovascular events (Marazziti et al., 1990; Jönsson et al., 2015; Hirokawa et al., 2016).

A recent review of literature underlined how unemployment, extended work hours, job instability, low wages, job strain, and sleep disorders were linked to an increased risk of HT (Cuffee et al., 2014). Recently, some authors (Trudel et al., 2016) evaluated the effect of repeated job strain and effort-reward imbalance (ERI; Siegrist, 1996) reporting that men chronically exposed to an active job, compared with not exposed men, presented a cumulative incidence of HT over 5 years. On the other hand, women who had experienced onset of ERI exposure were found to have a higher systolic ambulatory BP, in contrast with non-exposed women. Some authors reported a positive significant association between job strain and arterial stiffness in working men, while they did not found the same evidences in women, and others, instead, reported a negative association in a group of healthy male employees (Nordstrom et al., 2001; Hintsanen et al., 2005; Nomura et al., 2005; Bugajska et al., 2008).

Epidemiological studies have repeatedly investigated the association between anxiety and HT, with unclear results. Pan et al. (2015), in a recent systematic review and meta-analysis, summarized the current evidence from cross-sectional and 
prospective studies and their results suggest that there is an association between anxiety and increased risk of HT. These results support early detection and management of anxiety in hypertensive patients.

Depression is a significant and independent risk factor for HT, especially in young people (Shah et al., 2011; Jackson et al., 2016; Mermerelis et al., 2016). Depression could lower the heart rate variability, a normal feature of the heart rhythm: a too low value indicates a greater chance of dying as a result of CVDs. Again, the psychological condition may worsen the inflammatory response or raise the levels of blood cortisol (Shah et al., 2011). Amongst women its role seems to be even pair to traditional factors such as smoking, obesity, diabetes, and HT. Not surprisingly, Shah et al. (2011) observed that women with a history of suicide attempts present a greatest risk of dying from CVDs, three times more than the other (for males was 2.4 times higher than the other). Moreover, the authors have highlighted that these women have a 14 times greater risk of dying from heart attack (men stops to 3.5 times).

Nonetheless the growing body of evidences, the pathophysiological mechanisms underlying the relations between psychosocial factors and elevated BP remains still unclear or even contradictory and needs further investigation, especially in young people. Indeed, adolescents and young adults constitute a population with specific characteristics, which must be taken into account in the management of occupational risks (Caricati et al., 2016). In this sense, considering also the lifestyles that young people are taking in recent years, the evaluation of cardiovascular risk at early age is becoming increasingly important (Mangena et al., 2016).

Effort-rewarding balance could also explain the phenomenon of over identification in special groups of young people, such as health care profession students. In fact, these students experience-in addition to a repeated job strain - a continuous ERI for the whole course of studies due not only to the specific characteristics of a health care profession but, moreover, to the difficulty in entering into employment and in the precariousness of employment contracts. These problems may be even more evident in the current economic crisis (Van Hal, 2015).

Psychological wellbeing has consistently been shown to be related to job satisfaction (Wright et al., 2007; Merino and Privado, 2015). Melamed et al. (2001) have hypothesized that job complexity affects changes in BP levels and job satisfaction over 2-4 years of follow-up. Accordingly, job dissatisfaction has been reported to be an important and powerful source of psychological strain, in particular associated to elevated BP in women with low levels of social support (Ford, 2014).

In particular, chronic exposure to stressors would trigger a vicious cycle consisting in changes of emotional set points. These changes would bolster chronic readiness for future stressors and, finally, culminate in chronically altered affective states and perceived stress. SNS is also involved, as emotional accommodations are actually able to affect its set points especially in shifting basal physiological arousal and altering resting or baseline BP levels (Ganzel et al., 2010; Ganzel and Morris, 2011; Ford, 2014). It has long been known that perceived dissatisfaction at work should be considered a relevant chronic stressor, directly involved either on mental and on physical health, especially BP (Lindgärde et al., 1987; Kivimäki et al., 2008; Virtanen et al., 2013). For these reasons, it has been proposed to check periodically the pulse of employees in order to perform a simple yet accurate screening of heart disease risk, specifically focusing their attention on working population of 50 years old and older (Mathile, 2013). Amongst this age-range, Wright et al. (2007) report that $\mathrm{BP}$ differences of $60 \mathrm{mmHg}$ (or more) are more risky for CVDs and that both employees and employers should be aware of the potential problems resulting. On the other hand, there is a lack of studies investigating screening of BP, chronic work stressors and anxiety in young people. Anyhow, studies of this kind may be relatively uneasy to perform due to the enormous number of variables involved, of confounding factors and of the umpteen existing methods (Rosenthal and Alter, 2012).

Therefore, the aim of this paper was to study the role of work-related stress and anxiety in the development of HT in a sample of young health care profession students and the potential consequences of early CVDs. While considering the literature analyzed above, poor student satisfaction and over-identification with University may be considered as stress-related factors. Based on theoretical and empirical arguments, we propose the following three hypotheses:

Hypothesis 1: Controlling for differences in gender and age, life style variables, and anxiety and stress-related variables, will be related to systolic pressure in a young population of students.

Hypothesis 2: Controlling for differences in gender and age, life style variables, and anxiety and stress-related variables, will be related to diastolic pressure in a young population of students.

Hypothesis 3: Controlling for differences in gender and age, life style variables, and anxiety and stress-related variables, will be related to the overall cardiovascular health and PP in a young population of students.

In investigating our hypotheses, we followed the recommendations of leading cardiovascular schools (Frese and Zapf, 1988; Kristensen, 1996; Kasl, 1998) of incorporating objective-based cardiovascular measurements in the study designs. Both SBP and DBP were considered separately since they seem differently related to $\mathrm{CHD}$, and, as an integrated measurement, with PP.

\section{MATERIALS AND METHODS}

Data were collected between 2015 and 2016. A survey was administered by resident physicians in occupational medicine to a consistent sample of European students of an Italian university. In total, 412 students-belonging to several health care profession courses-participated in the study: 283 participants were women $(68.7 \%)$ and 129 were men $(31.3 \%)$. The average age \pm standard deviation was $23.9 \pm 7.5$ years.

Moreover, besides the mandatory health surveillance pursuant to the Italian Legislative Decree no. 81/2008 and subsequent amendments, the occupational physicians of a large Italian 
University Hospital investigated with particular attention health behaviors and cardiovascular health of the participants.

DBP and SBP readings were obtained by using the same professional aneroid sphygmomanometer on each student's right arm in a seated position maintained for at least $5 \mathrm{~min}$ in a constant room temperature. The instrument, owned by the University Hospital, is regularly calibrated by professional technicians. The diastolic scores ranged between 70 and $90 \mathrm{mmHg}$; the systolic scores ranged between 100 and $170 \mathrm{mmHg}$.

Life-style variables were also investigated during the medical consultation. Smoking status was categorized into non-smoker, former smoker, or smoker. Drinking alcohol was categorized into non-drinker, occasional drinker, drinker.

The frequency of physical activity including sport, stretching exercise, and walking was dichotomously categorized into yes or not. BMI was calculated following the literature recommendation. Students' height and mass were measured during the medical examination.

\section{Instruments}

\section{The Anxiety Scale of the Italian Version of the General Health Questionnaire (GHQ-12)}

The Italian version of the scale assesses whether the respondent has recently experienced a particular symptom or behavior. Each item is rated on a 4-point scale (less than usual, no more than usual, rather more than usual, or much more than usual) measuring a perception of psychological distress. A higher score indicates a greater degree of psychological distress (Piccinelli et al., 1993).

\section{Student Satisfaction}

Overall student satisfaction was assessed on a single item: "How satisfied are you with your present studies?" A metaanalysis, in which single-item measures were correlated with scales measuring overall job satisfaction, found that single-item measures were sufficiently reliable (Wanous et al., 1997). This scale was adapted for the student setting.

\section{University Identification}

The present study aimed to use a specific model of identification, especially developed for students. We used a single-item graphic scale for the measurement of identification with university adapted by the study of Shamir and Kark (2010). The scale was based on conceiving of identification in terms of distance or overlap between entities in a cognitive space. The content, construct, and predictive validity of this single-item measure have previously been investigated (Shamir and Kark, 2010).

\section{Control Variables}

Gender and age were included as control variables because they have been identified as possible confounders of the relation between stress-related factors anxiety and BP as explained in the Section "Introduction."

\section{Procedure and Data Analysis}

Descriptive statistics, Pearson's $r$ correlation and hierarchical regressions were performed on the study data using SPSS version 20 (SPSS Inc., Chicago, IL, USA). We used hierarchical regression as an analytical strategy because it provides statistical tests that allow for predictive conclusions: (1) the power of each block of variables (i.e., demographics, lifestyle variables, and anxiety); (2) the unique relationship between each predictor within each block and the dependent variable; and (3) the predictors with the strongest relationship with the dependent variable across blocks of variables (Midgley and Urdan, 2001; Wolters, 2004).

In order to better highlight the incremental contribution of each psychological variable (anxiety, student satisfaction, and university identification), our analyses proceeded in three blocks; these blocks are shown in Tables 2-4. In the first block, we added demographic variables (age and gender). In the second block, we added lifestyles variables (smoking status, alcohol consumption, BMI, and sport/exercising). These were followed by psychological variables in the third block.

\section{RESULTS}

Descriptive statistics and the correlations between demographics, anxiety, stress-related factors, and BP are reported in Table $\mathbf{1}$.

Tables 2-4 show the results of the regression analyses. The first analysis was the hierarchical regression with SBP as dependent variable and with demographics in the first block and life style variables and anxiety related stress respectively in the second and third block. In the first block, demographic data account for $4 \%$ of variance in DBP, with only gender statistically significant. When lifestyle variables were added in the second block, the model was significant, and this dimensions accounted for increased $4 \%$ of variance with smoking status, alcohol consumption, and sport/exercising significant. Finally, when anxiety, student satisfaction, and university identification were added in the third block, the model was significant, and these dimensions accounted for a total of $11 \%$ of in variance. The final model pertains the significance of all variables with the only exception of smoking status. In anxiety, student satisfaction, and university identification resulted significant and increased the explained variance of $3 \%$ over demographics and lifestyle variables. All the psychological variables were significant in the explanation of the SBP. Interestingly, higher level of identification with university was associated positively with higher SBP.

The second analysis used DBP as dependent variable. Demographics accounted for $2 \%$ with the significant role played by gender. Lifestyle variables in the second block added 3\% of incremental variance with only sport/exercising significant. The final model in the third block with psychological variables added accounted for a total $7 \%$ of variance. University and identification and anxiety resulted significant, whereas student satisfaction not.

Finally, when PP was used as dependent variable, the model was significant, and the considered dimensions accounted for a total of $7 \%$ of variance. In the final model only gender and student satisfaction were significant pointing out the peculiar role played by this variables. No lifestyle variables were significant. 


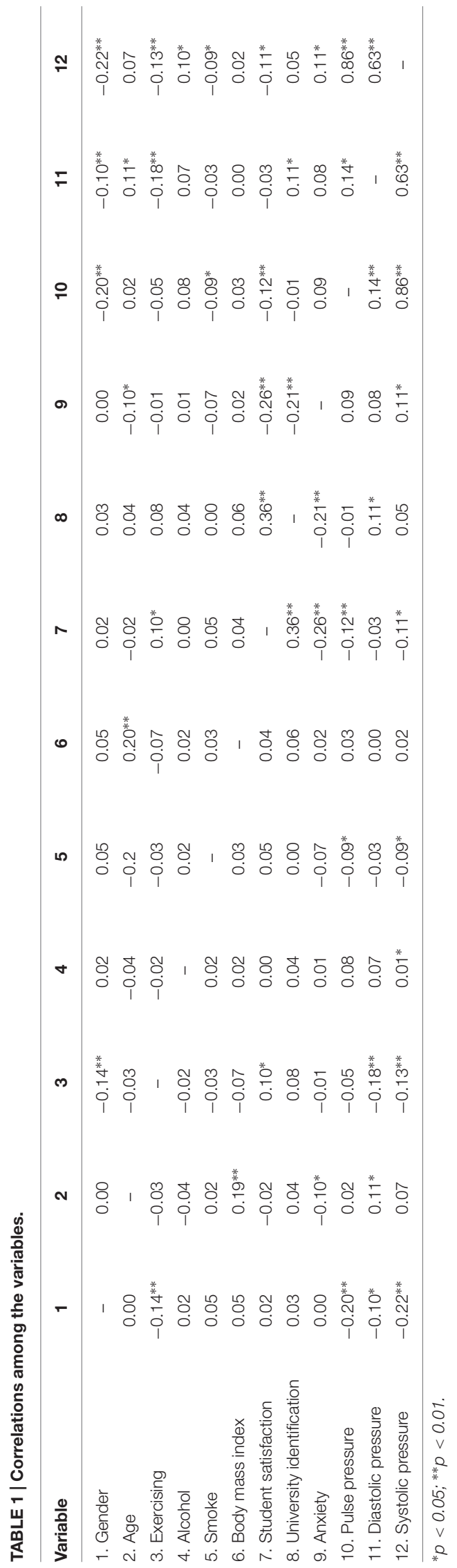

\section{DISCUSSION}

The models explain, as expected, a limited portion of the variance since the cardiovascular risk is considerably influenced by age. However, it is interesting to note that in such a young population (average age $23.9 \pm 7.5$ years old) these variables, in particular the psychological ones, may be related to an increase of the BP.

The present findings add further useful information and insight on the role of psychological stressors (and in particular student satisfaction) in determining young students BP and, therefore, cardiovascular health. These results seem to be in line with current literature (Backé et al., 2011; Hirokawa et al., 2016; Lazaridis et al., 2016), although this study is the first of its kind focusing on a sample of young students (average age $23.9 \pm 7.5$ years old), unlike the vast majority of the researches on cardiovascular risk and work-related stress. SBP appears to be significantly associated to anxiety and to university identification as well as to alcohol use and to sport/exercise (hypothesis 1). University identification and anxiety resulted to be significantly associated to DBP along sport/exercise and gender (hypothesis 2). Gender and student satisfaction were significantly associated to PP (hypothesis 3). Amongst demographic variables, life styles appear important and, in particular, sport/exercising appear significant $(p<0.001)$ in both the first and the second model.

In fact, the evidence of the several benefits provided by physical activity either on cardiovascular and internal diseases or on psychosocial disorders is well known and exhaustively described in scientific literature. Scott (1960) hypothesized that physical activity would ameliorate anxiety by becoming a sort of distraction from its symptoms and that following a healthy lifestyle may improve social contacts in patients and, therefore, the feedback from their environment.

Positive effects of physical activity on people who experienced normal or increased anxiety levels have been reported in several randomized trials (Bartley et al., 2013; Wegner et al., 2014; Pedersen and Saltin, 2015). Herring et al. (2010), comparing 40 studies in a meta-analysis, infer that anxiety symptoms in people suffering from chronic illnesses, such as CVDs, can be reduced by physical exercise.

Evidence of clinically relevant lowering of $\mathrm{BP}$ in hypertensive subjects engaged in physical training is larger and several metaanalyses are in agreement with the results of beneficial effect of physical activity on resting BP (Fagard and Cornelissen, 2007; Cornelissen et al., 2013; Garcia-Hermoso et al., 2013; Carlson et al., 2014; Huang et al., 2014). Neurohormonal, vascular, and structural adaptation mechanisms seem to be triggered by physical exercise and involved in the lowering effect of BP (Predel et al., 2001). Shah et al. (2016), considering a cohort of more than 4,000 young adults followed for an average of 26.9 years, have highlighted the importance of cardiorespiratory fitness as an independent risk factor for CVDs, and found a reduction of $15 \%$ of total mortality and $12 \%$ of the first cardiovascular event in three decades for each minute of exercise.

A complete understanding of the underlying nature of the existing relationships amongst job strain, identification, satisfaction, work stress, anxiety, and HT remains still unclear and difficult to comprehend because of the several complicated 
TABLE 2 | Hierarchical regression with SBP as criterion variable.

\begin{tabular}{lccc}
\hline & \multicolumn{3}{c}{ SBP } \\
\cline { 2 - 4 } Predictors & Block 1 & Block 2 & Block 3 \\
\hline Age & 0.07 & 0.07 & 0.07 \\
Gender & $-0.21^{* * *}$ & $-0.23^{* * *}$ & $-0.23^{* * *}$ \\
Alcohol consumption & - & $0.10^{*}$ & $0.10^{*}$ \\
BMl & - & 0.01 & 0.00 \\
Smoking status & - & $-0.08^{*}$ & -0.07 \\
Sport/exercising & - & $-0.16^{* * *}$ & $-0.16^{* * *}$ \\
Anxiety & - & - & $0.11^{*}$ \\
Student satisfaction & - & - & $-0.12^{*}$ \\
University identification & - & - & $0.10^{*}$ \\
$R^{2}$ & $0.04^{* * *}$ & $0.08^{* * *}$ & $0.11^{* * *}$ \\
$\Delta R^{2}$ & - & $0.04^{* * *}$ & $0.03^{* * *}$ \\
\hline$* p<0.05 ; * * * p<0.001$. & & &
\end{tabular}

TABLE 3 | Hierarchical regression with DBP as criterion variable.

\begin{tabular}{lccc}
\hline & \multicolumn{3}{c}{ DBP } \\
\cline { 2 - 4 } Predictors & Block 1 & Block 2 & Block 3 \\
\hline Age & $0.10^{*}$ & $0.11^{*}$ & $0.12^{*}$ \\
Gender & $-0.10^{*}$ & $-0.13^{* *}$ & $-0.13^{* *}$ \\
Alcohol consumption & - & 0.07 & 0.06 \\
BMl & - & -0.02 & -0.02 \\
Smoking status & - & -0.03 & -0.03 \\
Sport/exercising & - & $-0.20^{* * *}$ & $-0.21^{* * *}$ \\
Anxiety & - & - & $0.11^{*}$ \\
Student satisfaction & - & - & 0.02 \\
University identification & - & - & $0.15^{* *}$ \\
$R^{2}$ & $0.02^{* *}$ & $0.05^{* * *}$ & $0.07^{* * *}$ \\
$\Delta R^{2}$ & - & $0.03^{* * *}$ & $0.02^{* * *}$ \\
\hline$* p<0.05 ; * * p<0.01 ; * * * p<0.001$. & &
\end{tabular}

and confounding factors (Pan et al., 2015; Jackson et al., 2016; Maatouk et al., 2016). At the same time, it represents a challenging opportunity to earlier identify possible risk factors and, possibly, novel intervention strategies especially in the young population, that is in the study of cardiovascular risk.

It is noteworthy that the identification factor with university appeared to be positively related to elevated BP. Although it is difficult to establish an accurate underlying mechanism we may speculate that, possibly, an excessive identification results to be more stressful for the students and eventually expressing itself in a rise of the pressure values. In spite of the fact that several authors have been trying to investigate on the impact of stressful psychosocial work environments on health, focusing in particular on the ERI model (Siegrist, 1996) that combines extrinsic and intrinsic factors in studying work-related health (Birgit et al., 2013; Rasmussen et al., 2016; Siegrist and Li, 2016), available data in students and young people are meager. The concept of social reciprocity is the main core of the ERI model whereby money, esteem, and career opportunities (promotion and job security) become rewards achieved throughout job efforts. According to
TABLE 4 | Hierarchical regression with pulse pressure as criterion variable.

\begin{tabular}{lccc}
\hline & \multicolumn{3}{c}{ Pulse pressure } \\
\cline { 2 - 4 } Predictors & Block 1 & Block 2 & Block 3 \\
\hline Age & $0.10^{*}$ & 0.01 & 0.01 \\
Gender & $-0.10^{*}$ & $-0.20^{* * *}$ & $-0.21^{* * *}$ \\
Alcohol consumption & - & 0.08 & 0.08 \\
BMl & - & 0.02 & 0.02 \\
Smoking status & - & $-0.09^{*}$ & -0.08 \\
Sport/exercising & - & -0.08 & -0.07 \\
Anxiety & - & - & 0.05 \\
Student satisfaction & - & - & $-0.12^{*}$ \\
University identification & - & $0.05^{* * *}$ & 0.06 \\
$R^{2}$ & $0.03^{* *}$ & $0.02^{* * *}$ & $0.07^{* * *}$ \\
$\Delta R^{2}$ & - & & $0.02^{* * *}$ \\
\hline$* p<0.05 ; * * p<0.01 ; * * * p<0.001$. & &
\end{tabular}

the ERI model, an elevated job effort combined with a poor reward (lack of reciprocity) triggers consistent negative emotions and stress responses that finally result in adverse long-term effects on health. People who show an excessive engagement and a desire of being in control when trying to cope with exacting work situations are expected to exhibit a high susceptibility to these stress responses ("over-commitment", OC; Siegrist and Li, 2016). If we hypothesize to apply the ERI model to an excessive identification in university, our finding would result to be in line with the bulk of studies proving the association between $\mathrm{OC}$ and elevated SBP over time (Gilbert-Ouimet et al., 2012; Trudel et al., 2013; Xu et al., 2013).

Moreover, over-committed people show elevated levels of atherogenic lipids, glucose, and fibrinogen, increased proinflammatory activity, and decreased activity of natural killer cells and suffer from fatigue and insomnia. Weiner (1992) hypothesized the existence of an underlying and chronic arousal of the sympathetic-adrenergic system not equilibrated by restoring recovery processes provided by the parasympathetic nervous system. On the other hand, an individual may independently develop overindulgence with his/her work, in presence of increasing self-imposed demands and inability to regulate his/her work habits. Robinson (1998) interpreted this condition as workaholism, pointing out that it becomes problematic when the need to work becomes excessive to the point to create a substantial interference with personal health, happiness, family relationships, and social functioning. Workaholic people develop initially aggressiveness, elevated inner tension, and inability to relax (Marazziti et al., 2014) and, subsequently, either psychiatric symptoms such as anxiety, depression, and irritability, either physical problems such as HT, heart and kidney complications (Elowe, 2010).

It is noteworthy that in our study the only significant variable for $\mathrm{PP}$-in addition to the gender (which is the control anyway) - is the student satisfaction. This variable is crucial to the institutional success: an effective institution has satisfied "customers." In such a context, the satisfaction of the students may have several implications. First of all, satisfied students are more likely to continue their studies and achieve success positions 
in academia. This is crucial to improve the financial position and reputation of the University. In addition, a high student satisfaction may be also useful to attract new students, which in turn may increase the University's reputation (Aherne et al., 2016; Grilo Diogo et al., 2016).

Several theories have been proposed in an effort to better understanding the psychosocial dynamics of student satisfaction. For example, the happy-productive student theory (Cotton et al., 2002) suggests that student satisfaction is mediated by psychosocial factors such as coping, stress and well-being. Based on this theory, the authors provided evidence that high levels of psychological distress at university related to lower satisfaction. There is a need to identify and manage the causes of dissatisfaction among students in order to improve their psychological state.

The investment model explains the relationship between student satisfaction, dropout, and academic performance. Satisfaction increases when the rewards of study increase (higher grades; Hatcher et al., 1992). The model allows an early identification of students at risk of dropout, as well as to implement specific interventions with proper counseling and support measures.

There is also a third approach, which is based on the theory of consumer satisfaction (Churchill and Surprenant, 1982). It considers the satisfaction as a function of the extent to which the expectations of the students are positively confirmed during their course of study.

Some limitations of our study should be acknowledged. First of all, it cannot prove causality since its design was crosssectional. Consequently, the use of a longitudinal design is suggested. A second limitation is the use of some single-item research tools; similarly, the stress construct could be better defined (e.g., workload, support of the leaders, etc.). However, we are of the opinion that the collection and the processing of data were easy and more accessible. A third limitation concerns the sample that is not representative of the population of the Italian university students. In fact, our sample consisted of students from one university only, albeit from several health care profession degree courses. A fourth limitation relates to student satisfaction, which is not strictly a stress factor. However, different studies showed how it is an important determinant of a state of wellbeing (Warr, 1990; Faragher et al., 2005; Schéle et al., 2012; Alexopoulos et al., 2014). A fifth limitation is the single-time and manual measurement of BP. A dynamic monitoring of BP in the $24 \mathrm{~h}$ would have provided more reliable results but, at the same time, would have reduced students' participation in the research, because it is a method not widely accepted. Finally, the explained variance, as already explained above, is low. However, since the pressure values are usually low in people in the age range of our sample, we were expecting an even lower explained variance. Moreover, we observed that other studies, in which the parameter of BP was evaluated in combination with stress (e.g., Ford, 2014), did not report high associations also.

The present study definitely deserves follow-up to reach its assigned purposes, in particular by widening the sample and by extending the research to other university students. It would be interesting to evaluate also the consumption of caffeine from the students. On this topic the research perspectives are interesting. For example, a recent Italian study (Palatini et al., 2016) — which involved more than 1,200 patients over 12 years-showed that the heavy coffee drinkers show a risk of cardiovascular events (especially myocardial infarction) four times higher than nondrinkers, while moderate coffee drinkers they have a tripled risk. These effects could be mediated by the long-term influence of caffeine on BP and glucose metabolism (Palatini et al., 2016). However, coffee is not the only source of intake of caffeine. Especially in young people it is necessary to carefully evaluate the consumption of sugary drinks containing caffeine and, in particular, high caffeine content drinks (energy drinks), whose sales have increased worldwide over the past decade (Harris and Munsell, 2015; Brothers et al., 2016; Katz, 2016). Finally, it may need to consider other psychological variables, such as emotional intelligence (Di Fabio, 2014, 2015). Recently, Cabello and Fernández-Berrocal (2015) found that women and young adults in general were more likely to be incremental theorists than men and older adults. Furthermore, they found that emotion and emotional intelligence theories mediated the relationship of gender and age with ability emotional intelligence.

We are confident that our results, confirming the three innovative hypotheses, may be profitably transferred within the University organizations not only as an instrument of risk assessment-mandatory under the laws of EU countries (e.g., the Italian Legislative Decree n. 81/2008 and subsequent amendments) - but also, and moreover, to improve their institutional success. With this in mind, we believe that universities should adopt strategies encompassing the consultation of occupational physicians and industrial psychologists, aimed at assessing the satisfaction of health care profession students and at promoting their health. For the first aspect it may be useful, for example, providing constantly updated information about the professional opportunities of each study profile, encourage meetings with the world of work (especially, but not only, with the University hospitals), predispose strategies of stress management training and organize interventions for the prevention of dropouts. As far as the second aspect is concerned, the data collected during the health surveillance of students (such as BP) are a first, valuable, source for developing health promotion programs in both group and individual levels.

\section{AUTHOR CONTRIBUTIONS}

NM, GG, SDPC, JF-P, FM, and GA equally contributed to all the following issues of the research: conception and design of the work; acquisition, analysis, or interpretation of data for the work; drafting the work and critically revising it; final approval of the version to be published; agreement to be accountable for all aspects of the work in ensuring that questions related to the accuracy or integrity of any part of the work are appropriately investigated and resolved. 


\section{REFERENCES}

Aherne, D., Farrant, K., Hickey, L., Hickey, E., McGrath, L., and McGrath, D. (2016). Mindfulness based stress reduction for medical students: optimising student satisfaction and engagement. BMC Med. Educ. 16:209. doi: 10.1186/s12909-016-0728-8

Alexopoulos, E. C., Palatsidi, V., Tigani, X., and Darviri, C. (2014). Exploring stress levels, job satisfaction, and quality of life in a sample of police officers in Greece. Saf. Health Work 5, 210-215. doi: 10.1016/j.shaw.2014.07.004

Backé, E. M., Seidler, A., Latza, U., Rossnagel, K., and Schumann, B. (2011). The role of psychosocial stress at work for the development of cardiovascular diseases: a systematic review. Int. Arch. Occup. Environ. Health 85, 67-79. doi: 10.1007/s00420-011-0643-6

Baldasseroni, A., Abrami, V., Arcangeli, G., Cupelli, V., Fioriti, M., Guarducci, L., et al. (2005). Longitudinal study for assessing the efficacy of preventive measures in a population of health workers exposed to the risk of patient lifting. G. Ital. Med. Lav. Ergon. 27, 101-105.

Bartley, C. A., Hay, M., and Bloch, M. H. (2013). Metaanalysis: aerobic exercise for the treatment of anxiety disorders. Prog. Neuropsychopharmacol. Biol. Psychiatry 45, 34-39. doi: 10.1016/j.pnpbp.2013.04.016

Birgit, E., Gunnevi, S., and Ann, Ö (2013). Work experiences among nurses and physicians in the beginning of their professional careers - analyses using the effort-reward imbalance model. Scand. J. Caring Sci. 27, 36-43. doi: 10.1111/j.1471-6712.2012.00997.x

Blacher, J., Staessen, J. A., Girerd, X., Gasowski, J., Thijs, L., Liu, L., et al. (2000). Pulse pressure not mean pressure determines cardiovascular risk in older hypertensive patients. Arch. Intern. Med. 160, 1085-1089. doi: 10.1001/archinte.160.8.1085

Brothers, R. M., Christmas, K. M., Patik, J. C., and Bhella, P. S. (2016). Heart rate, blood pressure and repolarization effects of an energy drink as compared to coffee. Clin. Physiol. Funct. Imaging doi: 10.1111/cpf.12357 [Epub ahead of print].

Bugajska, J., Widerszal-Bazyl, M., Radkiewicz, P., Pasierski, T., Szulczyk, G. A., Zabek, J., et al. (2008). Perceived work-related stress and early atherosclerotic changes in healthy employees. Int. Arch. Occup. Environ. Health 81, 1037-1043. doi: 10.1007/s00420-007-0297-6

Cabello, R., and Fernández-Berrocal, P. (2015). Implicit theories and ability emotional intelligence. Front. Psychol. 6:700. doi: 10.3389/fpsyg.2015. 00700

Caricati, L., Chiesa, R., Guglielmi, D., and Mariani, M. G. (2016). Real and perceived employability: a comparison among Italian graduates. J. High. Educ. Policy Manag. 38, 490-502. doi: 10.1080/1360080X.2016.1182668

Carlson, D. J., Dieberg, G., Hess, N. C., Millar, P. J., and Smart, N. A. (2014). Isometric exercise training for blood pressure management: a systematic review and meta-analysis. Mayo Clin. Proc. 89, 327-334. doi: 10.1016/j.mayocp.2013.10.030

Churchill, G. A., and Surprenant, C. (1982). An investigation into the determinants of customer satisfaction. J. Mark. Res. 9, 491-504. doi: 10.2307/3151722

Cornelissen, V. A., Buys, R., and Smart, N. A. (2013). Endurance exercise beneficially affects ambulatory blood pressure: a systematic review and metaanalysis. J. Hypertens. 31, 639-648. doi: 10.1097/HJH.0b013e32835ca964

Cotton, S. J., Dollard, M. F., and de Jonge, J. (2002). Stress and student job design: satisfaction, well-being, and performance in university students. Int. J. Stress Manag. 9, 147-162. doi: 10.1023/A:1015515714410

Cuffee, Y., Ogedegbe, C., Williams, N. J., Ogedegbe, G., and Schoenthaler, A. (2014). Psychosocial risk factors for hypertension: an update of the literature. Curr. Hypertens. Rep. 16, 483. doi: 10.1007/s11906-014-0483-483

Di Fabio, A. (2014). Intrapreneurial self-capital: a new construct for the $21 \mathrm{st}$ century. J. Employ. Couns. 51, 98-111. doi: 10.1002/j.2161-1920.2014.00045.x

Di Fabio, A. (2015). Beyond fluid intelligence and personality traits in social support: the role of ability based emotional intelligence. Front. Psychol. 6:395. doi: 10.3389/fpsyg.2015.00395

Elowe, J. (2010). Workaholism: between illusion and addiction. Encephale 36, 285-293. doi: 10.1016/j.encep.2009.12.002

Fagard, R. H., and Cornelissen, V. A. (2007). Effect of exercise on blood pressure control in hypertensive patients. Eur. J. Cardiovasc. Prev. Rehabil. 14, 12-17. doi: 10.1097/HJR.0b013e3280128bbb
Falaschetti, E., Mindell, J., Knott, C., and Poulter, N. (2014). Hypertension management in England: a serial cross-sectional study from 1994 to 2011. Lancet 383, 1912-1919. doi: 10.1016/S0140-6736(14)60688-7

Faragher, E. B., Cass, M., and Cooper, C. L. (2005). The relationship between job satisfaction and health: a meta-analysis. Occup. Environ. Med. 62, 105-112. doi: 10.1136/oem.2002.006734

Ferguson, T. S., Younger, N. O., Tulloch-Reid, M. K., Wright, M. B., Ward, E. M., Ashley, D. E., et al. (2008). Prevalence of prehypertension and its relationship to risk factors for cardiovascular disease in Jamaica: analysis from a cross-sectional survey. BMC Cardiovasc. Disord. 8:20. doi: 10.1186/14712261-8-20

Floyd, C. N. (2015). Hypertension - state of the art 2015. Clin. Med. (Lond). 16, 52-54. doi: 10.7861/clinmedicine.16-1-52

Ford, M. T. (2014). Perceived unfairness at work, social and personal resources, and resting blood pressure. Stress Health 30, 12-22. doi: 10.1002/smi.2491

Frese, M., and Zapf, D. (1988). "Methodological issues in the study of work stress: objective vs subjective measurement of work stress and the question of longitudinal studies," in Causes, Coping and Consequences of Stress at Work, eds C. L. Cooper and R. Payne (New York, NY: John Wiley \& Sons), 375-387.

Ganzel, B. L., and Morris, P. A. (2011). Allostasis and the developing human brain: explicit consideration of implicit models. Dev. Psychopathol. 23, 955-974. doi: 10.1017/S0954579411000447

Ganzel, B. L., Morris, P. A., and Wethington, E. (2010). Allostasis and the human brain: Integrating models of stress from the social and life sciences. Psychol. Rev. 117, 134-174. doi: 10.1037/a0017773

Garcia-Hermoso, A., Saavedra, J. M., and Escalante, Y. (2013). Effects of exercise on resting blood pressure in obese children: a meta-analysis of randomized controlled trials. Obes. Rev. 14, 919-928. doi: 10.1111/obr.12054

Gilbert-Ouimet, M., Brisson, C., Vézina, M., Milot, A., and Blanchette, C. (2012). Repeated exposure to effort-reward imbalance, increased blood pressure, and hypertension incidence among white-collar workers: effortreward imbalance and blood pressure. J. Psychosom. Res. 72, 26-32. doi: 10.1016/j.jpsychores.2011.07.002

Graham, N., and Smith, D. J. (2016). Comorbidity of depression and anxiety disorders in patients with hypertension. J. Hypertens. 34, 397-398. doi: 10.1097/HJH.0000000000000850

Grilo Diogo, P., Moreira, A., Coimbra, A., Coelho Silva, A., Nixon Martins, A., Mendonça, C., et al. (2016). Study on portuguese medical schools' learning conditions: a national analysis on student satisfaction, student-tutor ratios and number of admissions. Acta Med. Port. 29, 301-309. doi: 10.20344/amp.6795

Hansen, M. L., Gunn, P. W., and Kaelber, D. C. (2007). Underdiagnosis of hypertension in children and adolescents. JAMA 298, 874-879. doi: 10.1001/jama.298.8.874

Harris, J. L., and Munsell, C. R. (2015). Energy drinks and adolescents: what's the harm? Nutr. Rev. 73, 247-257. doi: 10.1093/nutrit/nuu061

Hatcher, L., Kryter, K., Prus, J. S., and Fitzgerald, V. (1992). Predicting college student satisfaction, commitment, and attrition from investment model constructs. J. Appl. Soc. Psychol. 22, 1273-1296. doi: 10.1111/j.15591816.1992.tb00950.x

Herring, M. P., O'Connor, P. J., and Dishman, R. K. (2010). The effect of exercise training on anxiety symptoms among patients: a systematic review. Arch. Intern. Med. 170, 321-331. doi: 10.1001/archinternmed.2009.530

Hintsanen, M., Kivimäki, M., Elovainio, M., Pulkki-Råback, L., Keskivaara, P., Juonala, M., et al. (2005). Job strain and early atherosclerosis: the cardiovascular risk in young finns study. Psychosom. Med. 67, 740-747. doi: 10.1097/01.psy.0000181271.04169.93

Hirokawa, K., Ohira, T., Nagayoshi, M., Kajiura, M., Imano, H., Kitamura, A., et al. (2016). Occupational status and job stress in relation to cardiovascular stress reactivity in Japanese workers. Prev. Med. Rep. 4, 61-67. doi: 10.1016/j.pmedr.2016.05.010

Hodgkinson, J. A., Tucker, K. L., Martin, U., Beesley, L., and McManus, R. J. (2015). The use of ambulatory blood pressure measurement. Br. J. Hosp. Med. (Lond). 76, 631-637. doi: 10.12968/hmed.2015.76.11.631

Hosey, G. M., Samo, M., Gregg, E. W., Padden, D., and Bibb, S. G. (2014). Socioeconomic and demographic predictors of selected cardiovascular risk factors among adults living in Pohnpei, Federated States of Micronesia. BMC Public Health 14:895. doi: 10.1186/1471-2458-14-895 
Huang, T., Larsen, K. T., Ried-Larsen, M., Moller, N. C., and Andersen, L. B. (2014). The effects of physical activity and exercise on brain-derived neurotrophic factor in healthy humans: a review. Scand. J. Med. Sci. Sports 24, 1-10. doi: 10.1111/sms.12069

Jackson, C. A., Pathirana, T., and Gardiner, P. A. (2016). Depression, anxiety and risk of hypertension in mid-aged women: a prospective longitudinal study. J. Hypertens. 34, 1959-1966. doi: 10.1097/HJH.00000000000 01030

James, D., Yates, J., and Ferguson, E. (2013). Can the 12-item general health questionnaire be used to identify medical students who might 'struggle' on the medical course? A prospective study on two cohorts. BMC Med. Educ. 13:48. doi: 10.1186/1472-6920-13-48

Jennings, G. L., and Touyz, R. M. (2013). Hypertension guidelines: more challenges highlighted by Europe. Hypertension 62, 660-665. doi: 10.1161/hypertensionaha.113.02034

Johansson, G., Evans, G. W., Cederström, C., Rydstedt, L. W., Fuller-Rowell, T., and Ong, A. D. (2012). The effects of urban bus driving on blood pressure and musculoskeletal problems: a quasi-experimental study. Psychosom. Med. 74, 89-92. doi: 10.1097/PSY.0b013e31823ba88f

Jönsson, P., Österberg, K., Wallergård, M., Hansen, A. M., Garde, A. H., Johansson, G., et al. (2015). Exhaustion-related changes in cardiovascular and cortisol reactivity to acute psychosocial stress. Physiol. Behav. 151, 327-337. doi: 10.1016/j.physbeh.2015.07.020

Kasl, S. V. (1998). Measuring job stressors and studying the health impact of the work environment: an epidemiologic commentary. J. Occup. Health Psychol. 34, 390-401. doi: 10.1037/1076-8998.3.4.390

Katz, D. L. (2016). Energy drink consumption in Israeli youth: Public health \& the perils of energetic marketing. Isr. J. Health Policy Res. 10, 9. doi: 10.1186/s13584016-0069-4

Kessler, R. C., Chiu, W. T., Demler, O., Merikangas, K. R., and Walters, E. E. (2005). Prevalence, severity, and comorbidity of 12-month DSM-IV disorders in the National Comorbidity Survey Replication. Arch. Gen. Psychiatry 62, 617-627. doi: 10.1001/archpsyc.62.6.617

Khamis, R. Y., Ammari, T., and Mikhail, G. W. (2016). Gender differences in coronary heart disease. Heart. Heartjnl 2014, 306463. doi: 10.1136/heartjnl2014-306463

Kivimäki, M., Ferrie, J. E., Shipley, M., Gimeno, D., Elovainio, M., de Vogli, R., et al. (2008). Effects on blood pressure do not explain the association between organizational justice and coronary heart disease in the Whitehall II study. Psychosom. Med. 70, 1-6. doi: 10.1097/PSY.0b013e31815aaca3

Kristensen, T. S. (1996). Job stress and cardiovascular disease: a theoretic critical review. J. Occup. Health. Psychol. 1, 246-260. doi: 10.1037/1076-8998.1. 3.246

Lazaridis, K., Jovanović, J., Jovanović, J., Šarac, I., and Jovanović, S. (2016). The impact of occupational stress factors on temporary work disability related to arterial hypertension and its complications. Int. J. Occup. Saf. Ergon. 2, 1-8. doi: 10.1080/10803548.2016.1179524

Leigh, J. P., and Du, J. (2012). Are low wages risk factors for hypertension? Eur. J. Public Health 22, 854-859. doi: 10.1093/eurpub/ckr204

Lewington, S., Clarke, R., Qizilbash, N., Peto, R., Collins, R., and Prospective Studies Collaboration. (2002). Age-specific relevance of usual blood pressure to vascular mortality: a meta-analysis of individual data for one million adults in 61 prospective studies. Lancet 360, 1903-1913. doi: 10.1016/S01406736(02)11911-8

Lindgärde, F., Furu, M., and Ljung, B. O. (1987). A longitudinal study on the significance of environmental and individual factors associated with the development of essential hypertension. J. Epidemiol. Community Health 41, 220-226. doi: 10.1136/jech.41.3.220

Maas, A. H. E. M., and Appelman, Y. E. A. (2010). Gender differences in coronary heart disease. Neth. Heart. J. 18, 598-602. doi: 10.1007/s12471-010-0 841-y

Maatouk, I., Herzog, W., Böhlen, F., Quinzler, R., Löwe, B., Saum, K. U., et al. (2016). Association of hypertension with depression, and generalized anxiety symptoms in a large population-based sample of older adults. J. Hypertens. 34, 1711-1720. doi: 10.1097/HJH.0000000000001006

Mancia, G., Fagard, R., Narkiewicz, K., Redon, J., Zanchetti, A., Böhm, M., et al. (2013). $2013 \mathrm{ESH} / \mathrm{ESC}$ guidelines for the management of arterial hypertension: the task force for the management of arterial hypertension of the European
Society of Hypertension (ESH) and of the European Society of Cardiology (ESC). Eur. Heart. J. 34, 2159-2219. doi: 10.1093/eurheartj/eht151

Mangena, P., Saban, S., Hlabyago, K. E., and Rayner, B. (2016). An approach to the young hypertensive patient. S. Afr. Med. J. 106, 36-38. doi: 10.7196/SAMJ.2016.v106i1.10329

Marazziti, D., Falcone, M. F., Rosa, C., and Ghione, S. (1990). Changes in serotoninergic mechanisms in essential hypertension. Ann. Ital. Med. Int. 5, 459-463.

Marazziti, D., Presta, S., Baroni, S., Silvestri, S., and Dell’Osso, L. (2014). Behavioral addictions: a novel challenge for psychopharmacology. CNS Spectr. 19, 486-495. doi: 10.1017/S1092852913001041

Mathile, C. (2013). Run Your Business, Don't Let It Run You. San Francisco, CA: Berrett-Koehler Publishers, Inc.

Melamed, S., Fried, Y., and Froom, P. (2001). The interactive effect of chronic exposure to noise and job complexity on changes in blood pressure and job satisfaction: a longitudinal study of industrial employees. J. Occup. Health Psychol. 6, 182-195. doi: 10.1037/1076-8998.6.3.182

Mennini, F. S., Marcellusi, A., von der Schulenburg, J. M., Gray, A., Levy, P., Sciattella, P., et al. (2015). Cost of poor adherence to anti-hypertensive therapy in five European countries. Eur. J. Health Econ. 16, 65-72. doi: 10.1007/s10198013-0554-4

Merino, M. D., and Privado, J. (2015). Does employee recognition affect positive psychological functioning and well-being? Span. J. Psychol. 18, E64. doi: $10.1017 /$ sjp. 2015.67

Mermerelis, A., Kyvelou, S. M., Vellinga, A., Papageorgiou, C., Stefanadis, C., and Douzenis, A. (2016). Association between anxiety and depression symptoms with resistant hypertension and central hemodynamics: a pilot study. Hellenic J. Cardiol. 57, 203-204. doi: 10.1016/j.hjc.2016.07.004

Midgley, C., and Urdan, T. (2001). Academic self-handicapping and achievement goals: a further examination. Contemp. Educ. Psychol. 26, 61-75. doi: 10.1006/ceps.2000.1041

Modrek, S., and Cullen, M. R. (2013). Health consequences of the 'Great Recession' on the employed: evidence from an industrial cohort in aluminum manufacturing. Soc. Sci. Med. 92, 105-113. doi: 10.1016/j.socscimed.2013.04.027

Nechita, F., Streba, C. T., Vere, C. C., Nechita, D., and Rogoveanu, I. (2014). Stress in romanian first year nursing students. Curr. Health Sci. J. 40, 210-213. doi: 10.12865/CHSJ.40.03.10

Nomura, K., Nakao, M., Karita, K., Nishikitani, M., and Yano, E. (2005). Association between work-related psychological stress and arterial stiffness measured by brachial-ankle pulse-wave velocity in young Japanese males from an information service company. Scand. J. Work Environ. Health 31, 352-359. doi: 10.5271/sjweh.918

Nordstrom, C. K., Dwyer, K. M., Merz, C. N., Shircore, A., and Dwyer, J. H. (2001). Work-related stress and early atherosclerosis. Epidemiology 12, 180-185. doi: 10.1097/00001648-200103000-00009

Palatini, P., Fania, C., Mos, L., Garavelli, G., Mazzer, A., Cozzio, S., et al. (2016). Coffee consumption and risk of cardiovascular events in hypertensive patients. Results from the HARVEST. Int. J. Cardiol. 212, 131-137. doi: 10.1016/j.ijcard.2016.03.006

Pan, Y., Cai, W., Cheng, Q., Dong, W., An, T., and Yan, J. (2015). Association between anxiety and hypertension: a systematic review and meta-analysis of epidemiological studies. Neuropsychiatr. Dis. Treat. 11, 1121-1130. doi: 10.2147/NDT.S77710

Pedersen, B. K., and Saltin, B. (2015). Exercise as medicine-evidence for prescribing exercise as therapy in 26 different chronic diseases. Scand. J. Med. Sci. Sports 25(Suppl.), 1-72. doi: 10.1111/sms.12581

Piccinelli, M., Bisoffi, G., Bon, M. G., Cunico, L., and Tansella, M. (1993). Validity and test-retest reliability of the Italian version of the 12-item General Health Questionnaire in general practice: a comparison between three scoring methods. Compr. Psychiatry 34, 198-205. doi: 10.1016/0010-440X(93)90048-9

Pilic, L., Pedlar, C. R., and Mavrommatis, Y. (2016). Salt-sensitive hypertension: mechanisms and effects of dietary and other lifestyle factors. Nutr. Rev 74, 645-658. doi: 10.1093/nutrit/nuw028

Poulter, N. R., Prabhakaran, D., and Caulfield, M. (2015). Hypertension. Lancet 386, 801-812. doi: 10.1016/S0140-6736(14)61468-9

Predel, H. G., Mainka, W., Schillings, W., Knigge, H., Montiel, J., Fallois, J., et al. (2001). Integrated effects of the vasodilating beta-blocker nebivolol on 
exercise performance, energy metabolism, cardiovascular and neurohormonal parameters in physically active patients with arterial hypertension. J. Hum. Hypertens. 15, 715-721. doi: 10.1038/sj.jhh.1001257

Pryjmachuk, S., and Richards, D. A. (2008). Predicting stress in pre-registration midwifery students attending a university in Northern England. Midwifery 24, 108-122. doi: 10.1016/j.midw.2006.07.006

Rasmussen, V., Turnell, A., Butow, P., Juraskova, I., Kirsten, L., Wiener, L., et al. (2016). Burnout among psychosocial oncologists: an application and extension of the effort-reward imbalance model. Psychooncology 25, 194-202. doi: 10.1002/pon.3902

Rau, R. (2006). The association between blood pressure and work stress: the importance of measuring isolated systolic hypertension. Work Stress 20, 84-97. doi: 10.1080/02678370600679447

Riese, H., Van Doornen, L. J., Houtman, I. L., and De Geus, E. J. (2004). Job strain in relation to ambulatory blood pressure, heart rate, and heart rate variability among female nurses. Scand. J. Work Environ. Health 30, 477-485. doi: $10.5271 /$ sjweh.837

Ritvanen, T., Louhevaara, V., Helin, P., Halonen, T., and Hänninen, O. (2003). Psychophysiological stress in high school teachers. Int. J. Occup. Med. Environ. Health 16, 255-264.

Robinson, B. E. (1998). Chained to the Desk. New York, NY: New York University Press.

Rosenthal, T., and Alter, A. (2012). Occupational stress and hypertension. J. Am. Soc. Hypertens. 6, 2-22. doi: 10.1016/j.jash.2011.09.002

Santulli, G. (2013). Epidemiology of cardiovascular disease in the 21st century: updated numbers and updated facts. J. Cardiovasc. Dis. Res. 1, 1-2.

Schéle, I. A., Hedman, L. R., and Hammarström, A. (2012). A model of psychosocial work environment, stress, and satisfaction among dental students in Sweden. J. Dent. Educ. 76, 1206-1217.

Scott, M. G. (1960). The contributions of physical activity to psychological development. Res. Q. 31, 307-320.

Shah, A. J., Veledar, E., Hong, Y., Bremner, J. D., and Vaccarino, V. (2011). Depression and history of attempted suicide as risk factors for heart disease mortality in young individuals. Arch. Gen. Psychiatry 68, 1135-1142. doi: 10.1001/archgenpsychiatry.2011.125

Shah, R. V., Murthy, V. L., Colangelo, L. A., Reis, J., Venkatesh, B. A., Sharma, R., et al. (2016). Association of fitness in young adulthood with survival and cardiovascular risk: the Coronary Artery Risk Development in Young Adults (CARDIA) Study. JAMA Intern. Med. 176, 87-95. doi: 10.1001/jamainternmed.2015.6309

Shamir, B., and Kark, R. (2010). A single-item graphic scale for the measurement of organizational identification. J. Occup. Organ. Psychol. 77, 115-123. doi: 10.1348/096317904322915946

Siegrist, J. (1996). Adverse health effects of high-effort/low-reward conditions. J. Occup. Health Psychol. 1, 27-41. doi: 10.1037/1076-8998. 1.1 .27

Siegrist, J., and Li, J. (2016). Associations of extrinsic and intrinsic components of work stress with health: a systematic review of evidence on the effortreward imbalance model. Int. J. Environ. Res. Public Health 13, E432. doi: 10.3390/ijerph13040432

Smith, P. M., Mustard, C. A., Lu, H., and Glazier, R. H. (2013). Comparing the risk associated with psychosocial work conditions and health behaviours on incident hypertension over a nine-year period in Ontario, Canada. Can. J. Public Health 104, e82-e86.

Sparrenberger, F., Cichelero, F. T., Ascoli, A. M., Fonseca, F. P., Weiss, G., Berwanger, O., et al. (2009). Does psychosocial stress cause hypertension? A systematic review of observational studies. J. Hum. Hypertens. 23, 12-19. doi: 10.1038/jhh.2008.74

Spruill, T. M. (2010). Chronic psychosocial stress and hypertension. Curr. Hypertens. Rep. 12, 10-16. doi: 10.1007/s11906-009-0084-8

Tanuseputro, P., Manuel, D. G., Leung, M., Nguyen, K., Johansen, H., and Canadian Cardiovascular Outcomes Research Team. (2003). Risk factors for cardiovascular disease in Canada. Can. J. Cardiol. 19, 1249-1259.

Tin, L. L., Beevers, D. G., and Lip, G. Y. (2002). Systolic vs diastolic blood pressure and the burden of hypertension. J. Hum. Hypertens. 16, 147-150. doi: 10.1038/sj.jhh.1001373
Trudel, X., Brisson, C., Milot, A., Masse, B., and Vézina, M. (2013). Psychosocial work environment and ambulatory blood pressure: independent and combined effect of demand-control and effort-reward imbalance models. Occup. Environ. Med. 2013, 815-822. doi: 10.1136/oemed-2013-101416

Trudel, X., Brisson, C., Milot, A., Masse, B., and Vézina, M. (2016). Adverse psychosocial work factors, blood pressure and hypertension incidence: repeated exposure in a 5-year prospective cohort study. J. Epidemiol. Community Health 70, 402-408. doi: 10.1136/jech-2014-204914

Van Hal, G. (2015). The true cost of the economic crisis on psychological well-being: a review. Psychol. Res. Behav. Manag. 8, 17-25. doi: 10.2147/PRBM.S44732

Ventura, H. O., and Lavie, C. J. (2016). Impact of comorbidities in hypertension. Curr. Opin. Cardiol. 31, 374-375. doi: 10.1097/HCO.00000000000 00302

Virtanen, M., Nyberg, S. T., Batty, G. D., Jokela, M., Heikkilä, K., Fransson, E. I., et al. (2013). Perceived job insecurity as a risk factor for incident coronary heart disease: systematic review and meta-analysis. BMJ 347, f4746. doi: $10.1136 /$ bmj.f4746

Wallace, L., Bourke, M. P., Tormoehlen, L. J., and Poe-Greskamp, M. V. (2015). Perceptions of Clinical Stress in Baccalaureate Nursing Students. Int. J. Nurs. Educ. Scholarsh. 12. doi: 10.1515/ijnes-2014-0056

Wanous, J. P., Reichers, A. E., and Hudy, M. J. (1997). Overall job satisfaction: how good are single-item measures? J. Appl. Psychol. 82, 247-252. doi: 10.1037/00219010.82.2.247

Warr, P. (1990). The measurement of well-being and other aspects of mental health. J. Occup. Organ. Psychol. 63, 193-210. doi: 10.1111/j.2044-8325.1990.tb00 521.x

Wegner, M., Helmich, I., Machado, S., Nardi, A. E., Arias-Carrion, O., and Budde, H. (2014). Effects of exercise on anxiety and depression disorders: review of metaanalyses and neurobiological mechanisms. CNS Neurol. Disord. Drug Targets 13, 1002-1014. doi: 10.2174/18715273136661406121 02841

Weiner, H. (1992). Perturbing the Organism: The Biology of Stressful Experience. Chicago, IL: Chicago University Press.

Wolters, C. A. (2004). Advancing achievement goal theory: using goal structures and goal orientations to predict students' motivation, cognition, and achievement. J. Educ. Psychol. 96, 236-250. doi: 10.1037/0022-0663.96. 2.236

Wright, B. R., Barbosa-Leiker, C., and Hoekstra, T. (2011). Law enforcement officer versus non-law enforcement officer status as a longitudinal predictor of traditional and emerging cardiovascular risk factors. J. Occup. Environ. Med. 53, 730-734. doi: 10.1097/JOM.0b013e318220c2da

Wright, T. A., Cropanzano, R., and Bonett, D. G. (2007). The moderating role of employee positive well-being on the relation between job satisfaction and job performance. J. Occup. Health Psychol. 12, 93-104. doi: 10.1037/10768998.12.2.93

Wright, T. A., and Diamond, J. W. (2006). Getting the pulse of your employees: the use of cardiovascular research in better understanding behavior in organizations. J. Organ. Behav. 27, 395-401. doi: 10.1002/ job.374

Xu, W., Yu, H., Hang, J., Gao, W., Zhao, Y., and Guo, L. (2013). The interaction effect of effort-reward imbalance and overcommitment on hypertension among Chinese workers: findings from SHISO study. Am. J. Ind. Med. 6, 1433-1441. doi: 10.1002/ajim.22254

Conflict of Interest Statement: The authors declare that the research was conducted in the absence of any commercial or financial relationships that could be construed as a potential conflict of interest.

Copyright (c) 2016 Mucci, Giorgi, De Pasquale Ceratti, Fiz-Pérez, Mucci and Arcangeli. This is an open-access article distributed under the terms of the Creative Commons Attribution License (CC BY). The use, distribution or reproduction in other forums is permitted, provided the original author(s) or licensor are credited and that the original publication in this journal is cited, in accordance with accepted academic practice. No use, distribution or reproduction is permitted which does not comply with these terms. 